\title{
An Alkaline Deep Eutectic Solvent Based on Potassium Carbonate and Glycerol as Pretreatment for the Isolation of Cellulose Nanocrystals from Empty Fruit Bunch
}

\author{
Pei Gie Gan, ${ }^{\mathrm{a}}$ Sung Ting Sam, ${ }^{\mathrm{a}, *}$ Muhammad Faiq Abdullah, ${ }^{\mathrm{a}}$ Mohd Firdaus Omar, ${ }^{\mathrm{b}}$ and \\ Lian See Tan ${ }^{c}$
}

\begin{abstract}
Cellulose nanocrystals (CNC) were successfully isolated from oil palm empty fruit bunch (EFB) using sulphuric acid hydrolysis preceded by alkaline deep eutectic solvent (DES) pretreatment and bleaching. In this study, an alkaline DES consisting of potassium carbonate and glycerol (molar ratio of 1:7) was used as the pretreatment solvent to promote the dissolution of lignin and hemicellulose. The processing parameters of acid hydrolysis were optimized using Box-Behnken Design. The results showed that the yield of CNC was $37.1 \%$, under the optimal conditions of $60.0 \mathrm{wt} \%$ acid concentration at $46.1{ }^{\circ} \mathrm{C}$ for $58.5 \mathrm{~min}$. The field emission scanning electron microscopy (FESEM), chemical composition analysis, and Fourier transform infrared (FTIR) results indicated that unwanted impurities, such as hemicellulose and lignin, were efficiently eliminated from the raw EFB fibers by DES pretreatment and bleaching. The average diameter of CNC was less than $10 \mathrm{~nm}$. The raw EFB fiber, treated cellulose, and CNC showed crystallinities of $38.7 \%, 51.2 \%$, and $65.3 \%$, respectively. The CNC had lower thermal stability, which was ascribed to the sulphate group present on the CNC surface.
\end{abstract}

Keywords: Empty fruit bunch; Cellulose nanocrystals; Optimization; Deep eutectic solvent; Acid hydrolysis

Contact information: a: School of Bioprocess Engineering, Universiti Malaysia Perlis, 02600 Arau, Perlis, Malaysia; $b$ : School of Material Engineering, Universiti Malaysia Perlis (UniMAP), Kompleks Pusat Pengajian Jejawi 2, 02600 Arau, Perlis; c: Department of Chemical Process Engineering, Malaysia-Japan International Institute of Technology, Universiti Teknologi Malaysia, 54100 Kuala Lumpur, Malaysia;

*Corresponding author: stsam@unimap.edu.my

\section{INTRODUCTION}

Cellulose can be considered the most abundant biopolymer on Earth that is natural, renewable, and biodegradable. The annual global biomass production is estimated to be around 220 billion tons on the dry basis (Islam et al. 2018). The interest in sustainability and green chemistry has led to great concern over cellulosic materials derived from various sources such as agricultural wastes, energy crops, and forestry sources (Mohanty et al. 2015). Agricultural residues, such as empty fruit bunch (EFB), with a cellulose content of approximately $40 \%$ to $50 \%$, have great potential as a lignocellulosic source to be converted into valuable products (Thakur 2014a).

Cellulose nanocrystals (CNC) are highly crystalline rod-like-shaped cellulosic nanoparticles with one dimension that is less than or equal to $100 \mathrm{~nm}$ (Li et al. 2018). They have received a tremendous level of interest due to their attractive features such as high aspect ratio, low density, excellent tensile properties, and high biodegradability (Cao 2018). There are various methods for preparing CNC, with sulphuric acid hydrolysis 
being the most popular and the most commonly used technique. Acid hydrolysis breaks the amorphous and disordered domains of the cellulose, enabling isolation of the compact and well-defined crystallites (Thakur 2014b). Moreover, the isolation of CNC using sulphuric acid also leads to a negatively charged crystallite surface resulting from esterification by sulphate ions after acid hydrolysis. As a result, a more stable CNC dispersion could be formed using sulphuric acid compared to other acids (Yang et al. 2017). Chao et al. (2016) reported that the sulphuric acid hydrolyzed CNC has a smaller diameter and better stability and dispersion compared to formic acid hydrolyzed CNC. The higher acidity of sulphuric acid resulted in a smaller diameter of CNC compared to formic acid. Besides, the formation of sulphate groups on the surface of CNC also led to a well-dispersed and more individualized cellulose than formic acid hydrolyzed CNC. The properties of CNC are greatly affected by the fiber's source and by hydrolysis conditions such as acid concentration, reaction time, and hydrolytic temperature. Razali et al. reported the influence of reaction time on CNC from EFB microcrystalline cellulose (Razali et al. 2017). However, the effects of acid concentration and hydrolytic temperature on EFB-CNC have not been fully elucidated yet.

Prior to the isolation of $\mathrm{CNC}$, pretreatments are necessary to dissolve noncellulosic components, such as lignin and hemicellulose, to increase the cellulose's accessibility for further treatments (Leite et al. 2017). Various pretreatments have been reported in previous literature, including physical (milling, ultrasound, and mechanical extrusion), biological, and chemical (ionic liquids, mild acid, and mild alkaline) (Singh et al. 2015). Recently, a new solvent known as deep eutectic solvent (DES) has appeared as an environmentally friendly alternative for the pretreatment of biomass material. It can form hydrogen bonds with lignin and hemicellulose by accepting and donating the protons; thus the solvation ability can be improved. A DES offers numerous favorable properties over ionic liquids and conventional solvents while overcoming their disadvantages. These properties include the ease of synthesis in which DES can be easily prepared from mixtures of components and hydrogen bond donor compounds at moderate temperature and atmospheric pressure, lower costs, and higher sustainability (Vanda et al. 2018). Furthermore, conventional pretreatments, such as mild alkaline pretreatment, involves higher processing costs due to the large amount of water needed to remove the salts from the biomass. Several kinds of research have evaluated the capabilities and efficiency of DES in the biomass pretreatments trials with excellent results (Xia et al. 2014; Draman et al. 2016a; Lynam et al. 2017). These properties make DES one of the most promising pretreatments for the production of sustainable biomaterial. A new type of alkaline DES in which potassium carbonate $\left(\mathrm{K}_{2} \mathrm{CO}_{3}\right)$ is used together with glycerol, which acts as a hydrogen bond donor, was found to have a high potential for different fields of application. This new $\mathrm{K}_{2} \mathrm{CO}_{3}$-based DES, discovered by Naser et al. (2013), has yet to be examined in any other chemical or biological application. Therefore, this research is a first attempt to explore the potential of $\mathrm{K}_{2} \mathrm{CO}_{3}$-based DES as the pretreatment for the isolation of cellulose nanocrystals.

The effect of conventional pretreatments, such as sodium hydroxide pretreatment and enzymatic hydrolysis pretreatment, on the isolation of $\mathrm{CNC}$ has been widely reported (Siqueira et al. 2010; Chieng et al. 2017); however, the application of $\mathrm{K}_{2} \mathrm{CO}_{3}$-based DES as a pretreatment and its subsequent impact on the properties of CNC has scarcely been studied. In this work, the influence of hydrolysis conditions on the CNC yield was studied using response surface methodology (RSM). Acid concentration, reaction time, and hydrolytic temperature were selected as the independent variables for a Box-Behnken 
experimental design. The morphological structure of the specimens was investigated by using field emission scanning electron microscopy (FESEM), atomic force microscopy (AFM), and transmission electron microscopy (TEM). The physical properties of cellulose specimens were examined using Fourier transform infrared (FTIR) spectroscopy, X-ray diffraction (XRD), and thermogravimetric analysis (TGA).

\section{EXPERIMENTAL}

\section{Materials}

The EFB was supplied by Taclico Company Pte Ltd. (Kedah, Malaysia). The chemical reagents employed in this work were sodium chlorite (Acros Organics, Geel, Belgium); sodium hydroxide (Sigma-Aldrich, St Louis, MO, USA); glacial acetic acid, potassium carbonate (HmbG Chemicals, Hamburg, Germany); glycerol, and sulphuric acid (Merck, Darmstadt, Germany). All chemicals were of analytical grade.

\section{Preparation of EFB-microcellulose (EFB-MC)}

The alkaline DES mixture was prepared by mixing potassium carbonate and glycerol at a mole ratio of 1:7 (potassium carbonate:glycerol) at $80{ }^{\circ} \mathrm{C}$ for $2 \mathrm{~h}$ until a homogeneous transparent liquid was formed. Then, $10 \mathrm{~g}$ of EFB was added into $200 \mathrm{~mL}$ $\mathrm{DES}$, and the mixture was heated at $80{ }^{\circ} \mathrm{C}$ for $2 \mathrm{~h}$. The bleaching treatment was conducted at a temperature of $80{ }^{\circ} \mathrm{C}$ for $2 \mathrm{~h}$. The bleaching solution was made via mixing equal parts of acetate buffer, distilled water, and $1.7 \mathrm{wt} \%$ chlorite solution. The acetic acid buffer was prepared by dissolving $40 \mathrm{~g}$ of $\mathrm{NaOH}$ pellets into a mixture of $75 \mathrm{~mL}$ glacial acetic acid and $925 \mathrm{~mL}$ distilled water. Both the DES and bleaching treatments were conducted three times to remove any impurities.

\section{Isolation of $\mathrm{CNC}$}

The CNC particles were isolated by sulphuric acid hydrolysis following the procedure described by Martelli-Tosi et al. (2018) with slight modification. Approximately $0.5 \mathrm{~g}$ of EFB-MC was added into the $\mathrm{H}_{2} \mathrm{SO}_{4}$ solution and heated on a magnetic hot plate under constant stirring. The hydrolysis was stopped by diluting with cold distilled water. The suspension was then centrifuged repeatedly at $9000 \mathrm{rpm}$ for 10 min. The suspension was centrifuged repeatedly until the supernatant became turbid. The CNC suspension was ultrasonicated for $10 \mathrm{~min}$ to prevent aggregation.

\section{Optimization conditions for preparation of $\mathrm{CNC}$}

The Box-Behnken design of response surface methodology (RSM) was used for optimizing the hydrolysis conditions of CNC using the software Design-Expert (Trial Version 7.0.0, Static Made Easy, Minneapolis, MN, USA). Statistical significance of the models was investigated using analysis of variance (ANOVA). The details of the independent variables for acid hydrolysis are tabulated in Table 1. 
Table 1. Parameter Levels of Box-Behnken Test

\begin{tabular}{|l|c|c|c|c|}
\hline \multicolumn{1}{|c|}{ Parameters } & Unit & $\begin{array}{c}\text { Low Level } \\
\mathbf{X}_{\mathbf{i}}=\mathbf{- 1}\end{array}$ & $\begin{array}{c}\text { Midrange Level } \mathbf{x}_{\mathbf{i}} \\
\mathbf{= 0}\end{array}$ & $\begin{array}{c}\text { High Level } \\
\mathbf{x}_{\mathbf{i}}=\mathbf{1}\end{array}$ \\
\hline Acid Concentration, $\mathbf{X}_{\mathbf{1}}$ & $\mathrm{wt} \%$ & 50 & 57.5 & 65 \\
\hline Hydrolytic Temperature, $\mathbf{X}_{\mathbf{2}}$ & ${ }^{\circ} \mathrm{C}$ & 40 & 50 & 60 \\
\hline Reaction Time, $\mathbf{X}_{\mathbf{3}}$ & $\mathrm{min}$ & 30 & 60 & 90 \\
\hline
\end{tabular}

The CNC yield was calculated according to Eq. 1:

$$
\text { Yield }(\%)=\frac{W_{d}}{W_{o}} \times 100
$$

\section{Methods}

Morphology characterization

The morphological characteristics of EFB cellulose were investigated using FESEM (NOVA NANOSEM 450; FEI, Hillsboro, Oregon, USA). The $0.001 \mathrm{wt} \%$ CNC was sonicated and dropped onto the sample holder and dried at room temperature. Prior to the examination, the specimens were sputtered with gold (Polaron SC Sputter Coater; Quorum Technologies, Uckfield, UK). All images were acquired using an accelerating voltage of $3 \mathrm{kV}$.

The morphology of the CNC was obtained using an AFM (Dimension Edge; Bruker, Santa Barbara, CA, USA) with tapping mode. Droplets of CNC suspension at $0.001 \mathrm{wt} \%$ were deposited on a silicon wafer and dried at room temperature prior to examination. The specimen was conducted at ambient relative humidity and temperature in the tapping mode with a resonance frequency equal to $300 \mathrm{kHz}$.

The size and structure of CNC were investigated with a LIBRA 120 transmission electron microscope (Carl Zeiss AG, Oberkochen, Germany). A droplet of CNC suspension was placed on a 400-mesh copper grid and held with self-locking forceps. Excess water was wicked using filter paper. The CNC was stained by using $2 \mathrm{wt} / \mathrm{v} \%$ of uranyl acetate solution. The average diameter and length of $\mathrm{CNC}$ were determined using Image J software (Version 1.37, National Institutes of Health, Bethesda, MD, USA). For this purpose, 50 celluloses were randomly selected.

\section{Chemical Composition Analysis}

The composition of the raw EFB, unbleached DES-treated cellulose and bleached DES-treated cellulose was determined according to the ASTM standards. The holocellulose content was determined according to ASTM D1104-56. The specimen was treated with $5 \mathrm{~g}$ of sodium chlorite and $2 \mathrm{~mL}$ of glacial acetic acid and heated at $70{ }^{\circ} \mathrm{C}$ for 4 hours. The suspension was filtered and washed with distilled water. The solid residue was dried in an oven until constant weight was reached. The dried holocellulose was used to investigate the cellulose content based on the ASTM D1103-60. The cellulose content was determined by treating the holocellulose with $17.5 \mathrm{wt} \%$ of sodium hydroxide solution. The suspension was filtered, washed, and dried in an oven until constant weight was obtained. The lignin content was measured according to the ASTM D1106-96. The specimen was treated with $3 \mathrm{~mL}$ of $72 \mathrm{wt} \%$ sulphuric acid at $30{ }^{\circ} \mathrm{C}$ for 2 hours. The suspension was then diluted to a concentration of $3 \mathrm{wt} \%$ and refluxed for another 2 hours. The solid residue was filtered, washed, and dried in an oven until constant weight was achieved. The average values of the triplicates were recorded. 


\section{FTIR spectroscopy}

The FTIR analysis was conducted using a Spectrum RX FTIR spectrophotometer (Perkin Elmer, Norwalk, VA, USA). The specimens were analyzed using the potassium bromide $(\mathrm{KBr})$ pellet technique in the wavenumber range from $4000 \mathrm{~cm}^{-1}$ to $450 \mathrm{~cm}^{-1}$ with a resolution of $4 \mathrm{~cm}^{-1}$.

\section{XRD analysis}

The crystalline phases of specimens were studied using a Bruker D2 Phaser X-ray diffractometer (Bruker, Santa Barbara, USA). The powdered samples were scanned within a $2 \theta$ range from $10^{\circ}$ to $40^{\circ}$ with a scanning rate of $0.33 \%$. The crystallinity index (CI) was determined from the XRD patterns using the peak height method according to Segal et al. (1959) or Eq. 2,

$$
\mathrm{CI}(\%)=\left[\left(I_{002}-I_{\mathrm{AM}}\right) / I_{002}\right] \times 100
$$

where $I_{002}$ is the overall peak intensity of crystalline material and $I_{\mathrm{AM}}$ is the minimum peak intensity of amorphous material.

\section{TGA analysis}

The thermal properties of the specimens were evaluated by using a TGA Q50 (TA Instruments, New Castle, DE, USA) under a nitrogen gas atmosphere. Approximately 10 $\mathrm{mg}$ of the specimens were heated from 25 to $600{ }^{\circ} \mathrm{C}$ at a heating rate of $10^{\circ} \mathrm{C} / \mathrm{min}$ using a platinum pan. The change in mass of the sample was recorded continuously with regards to temperature and time.

\section{RESULTS AND DISCUSSION}

\section{Statistical Analysis and Model Fitting}

The Box-Behnken design results and experimental yield are presented in Table 2.

Table 2. Design and Results of Box-Behnken Analysis

\begin{tabular}{|c|c|c|c|c|c|}
\hline No. & $\begin{array}{c}\text { Acid Concentration, } \\
\mathbf{X}_{\mathbf{1}}(\mathbf{w t} \%)\end{array}$ & $\begin{array}{c}\text { Hydrolytic } \\
\text { Temperature, } \mathbf{X}_{\mathbf{2}}\left({ }^{\circ} \mathbf{C}\right)\end{array}$ & $\begin{array}{c}\text { Reaction Time, } \\
\mathbf{X}_{\mathbf{3}}(\mathbf{m i n})\end{array}$ & $\begin{array}{c}\text { Predicted } \\
\text { Yield (\%) }\end{array}$ & $\begin{array}{c}\text { Yield } \\
(\%)\end{array}$ \\
\hline 1 & 50 & 40 & 60 & 27.99 & 26.97 \\
\hline 2 & 65 & 40 & 60 & 35.15 & 35.28 \\
\hline 3 & 50 & 60 & 60 & 28.62 & 28.49 \\
\hline 4 & 65 & 60 & 60 & 25.22 & 26.23 \\
\hline 5 & 50 & 50 & 30 & 26.12 & 26.87 \\
\hline 6 & 65 & 50 & 30 & 32.65 & 32.25 \\
\hline 7 & 50 & 50 & 90 & 30.87 & 31.27 \\
\hline 8 & 65 & 50 & 90 & 28.11 & 27.36 \\
\hline 9 & 57.5 & 40 & 30 & 29.95 & 30.22 \\
\hline 10 & 57.5 & 60 & 30 & 27.04 & 26.42 \\
\hline 11 & 57.5 & 40 & 90 & 31.79 & 32.41 \\
\hline 12 & 57.5 & 60 & 90 & 23.41 & 23.14 \\
\hline 13 & 57.5 & 50 & 60 & 36.46 & 36.92 \\
\hline 14 & 57.5 & 50 & 60 & 36.46 & 37.53 \\
\hline 15 & 57.5 & 50 & 60 & 36.46 & 35.88 \\
\hline 16 & 57.5 & 50 & 60 & 36.46 & 36.14 \\
\hline 17 & 57.5 & 50 & 60 & 36.46 & 35.81 \\
\hline
\end{tabular}


The relationship between the $\mathrm{CNC}$ yield and the three independent variables was calculated using Eq. 3, which was expressed in the coded factors,

$$
\begin{aligned}
Y= & 36.46+0.94 X_{1}-2.33 X_{2}+0.052 X_{3}-2.64 X_{1} X_{2}-2.32 X_{1} X_{3}-0.87 X_{2} X_{3}- \\
& 3.16 X_{1}^{2}-4.05 X_{2}^{2}-3.86 X_{3}^{2}
\end{aligned}
$$

where $\mathrm{Y}$ represents the yield of $\mathrm{CNC}$, and $\mathrm{X}_{1}, \mathrm{X}_{2}$, and $\mathrm{X}_{3}$ are the independent variables for acid concentration, hydrolytic temperature, and reaction time, respectively.

Table 3 presents the ANOVA for the response surface model. The model F-value of 34.71 and the model P-value of less than 0.0001 indicated that the model was greatly significant. The results showed that there was only a possibility of $0.01 \%$ that obtaining a model F-value this large could be due to noise. The $\mathrm{R}^{2}$ of the model was calculated as 0.978 for the CNC yield, which suggested that the model could explain $97.8 \%$ of the variability in the response. A regression model with an $\mathrm{R}^{2}$ higher than 0.90 implies a high degree of correlation between the variables (Duret et al. 2013). From Table 3, it was observed that $\mathrm{X}_{1}, \mathrm{X}_{2}, \mathrm{X}_{1} \mathrm{X}_{2}$, and $\mathrm{X}_{1} \mathrm{X}_{3}$, all had $\mathrm{P}$-values below 0.05 , which suggested significant effects on $\mathrm{CNC}$ yield. Furthermore, the quadratic terms $\left(\mathrm{X}_{1}^{2}, \mathrm{X}_{2}^{2}\right.$, and $\left.\mathrm{X}_{3}^{2}\right)$ were significant $(\mathrm{P}<0.0003)$, implying that the $\mathrm{CNC}$ yield was influenced significantly by the variables. In addition, the lack-of-fit was insignificant $(\mathrm{P}>0.05)$ relative to pure error, which meant that the model fitted well and there was a significant effect of the variables on the CNC yield.

Table 3. ANOVA Study for Response Surface Model of CNC Yield

\begin{tabular}{|c|c|c|c|c|c|c|}
\hline Source & $\begin{array}{c}\text { Sum of } \\
\text { Squares }\end{array}$ & Degree of Freedom & $\begin{array}{c}\text { Mean } \\
\text { Square }\end{array}$ & $\begin{array}{c}\mathbf{F}- \\
\text { value }\end{array}$ & $\begin{array}{c}\text { P- } \\
\text { value }\end{array}$ & Comments \\
\hline Model & 296.84 & 9 & 32.98 & 34.71 & $<0.0001$ & Significant \\
\hline $\mathbf{X}_{\mathbf{1}}$ & 7.07 & 1 & 7.07 & 7.44 & 0.0294 & - \\
\hline $\mathbf{X}_{\mathbf{2}}$ & 43.25 & 1 & 43.25 & 45.51 & 0.0003 & - \\
\hline $\mathbf{X}_{\mathbf{3}}$ & 0.02 & 1 & 0.02 & 0.02 & 0.8832 & - \\
\hline $\mathbf{X}_{\mathbf{1}} \mathbf{X}_{\mathbf{2}}$ & 27.93 & 1 & 27.93 & 29.40 & 0.0010 & - \\
\hline $\mathbf{X}_{\mathbf{1}} \mathbf{X}_{\mathbf{3}}$ & 21.58 & 1 & 21.58 & 22.71 & 0.0020 & - \\
\hline $\mathbf{X}_{\mathbf{2}} \mathbf{X}_{\mathbf{3}}$ & 3.01 & 1 & 3.01 & 3.17 & 0.1183 & - \\
\hline $\mathbf{X}_{\mathbf{1}}{ }^{2}$ & 42.09 & 1 & 42.09 & 44.30 & 0.0003 & - \\
\hline $\mathbf{X}_{\mathbf{2}}{ }^{2}$ & 69.12 & 1 & 69.12 & 72.75 & $<0.0001$ & - \\
\hline $\mathbf{X}_{\mathbf{3}}{ }^{2}$ & 62.63 & 1 & 62.63 & 65.91 & $<0.0001$ & - \\
\hline Residual & 6.65 & 7 & 0.95 & - & - & - \\
\hline Lack of Fit & 4.43 & 3 & 1.48 & 2.67 & 0.1836 & Not significant \\
\hline Pure Error & 2.22 & 4 & 0.55 & - & - & - \\
\hline
\end{tabular}

Figure 1(a) shows that the CNC yield steadily increased with increasing hydrolytic temperature from $40{ }^{\circ} \mathrm{C}$ to $50{ }^{\circ} \mathrm{C}$ at the same acid concentration before declining slightly. It was also observed that the yield of CNC initially increased with the increase of acid concentration. However, the yield subsequently decreased as the acid concentration was further increased over a constant reaction time. Figure 1(b) displays a distinct peak of the response, showing the CNC yield that also initially increased with the increase of time and acid concentration, respectively. The yield declined after crossing a certain level of acid concentration and reaction time. The spherical contour plot obtained indicated the substantial interaction between reaction time and acid concentration (Lu et al. 2013). The simultaneous dependence of CNC yield on the hydrolytic temperature and 
time is displayed in Fig. 1(c). The contour plot showed that when the time was prolonged from $30 \mathrm{~min}$ to $90 \mathrm{~min}$ at the same hydrolytic temperature, the $\mathrm{CNC}$ yield exhibited a similar trend as shown in Fig 1(b). For a constant reaction time, the yield of CNC increased when the hydrolytic temperature was raised from $40{ }^{\circ} \mathrm{C}$ to $47{ }^{\circ} \mathrm{C}$ but the $\mathrm{CNC}$ yield decreased at a higher hydrolytic temperature.
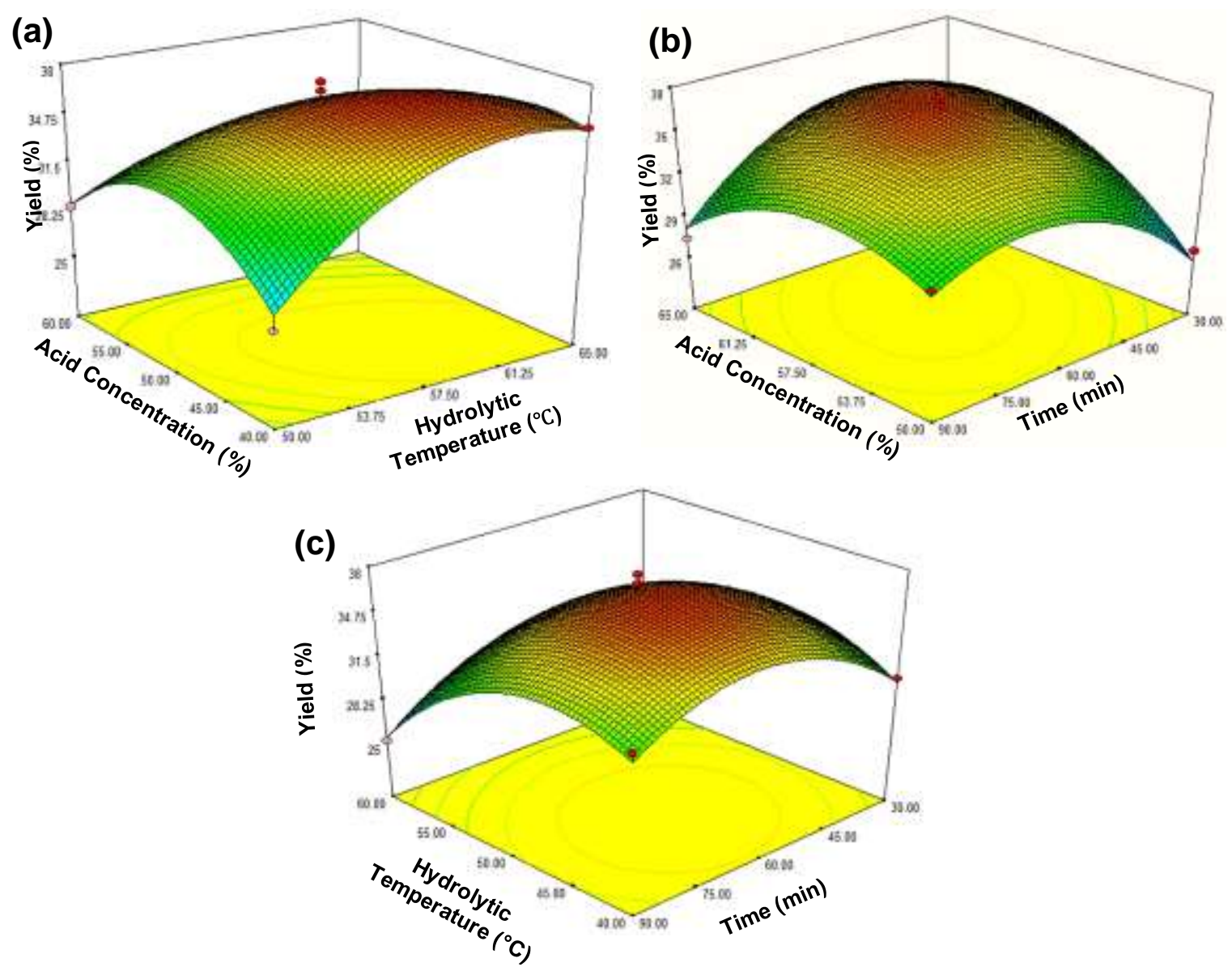

Fig. 1. Response surface and contour plots of (a) acid concentration and hydrolytic temperature, (b) acid concentration and time, and (c) hydrolytic temperature and time

The optimum conditions of acid hydrolysis were an acid concentration $60.0 \mathrm{wt} \%$, hydrolytic temperature $46.1{ }^{\circ} \mathrm{C}$, and reaction time $58.5 \mathrm{~min}$. Under the optimal conditions, the maximum yield of $\mathrm{CNC}$ was $37.1 \%$ as predicted by the response surface model.

\section{Morphology}

The SEM micrographs of raw EFB fiber and DES-treated cellulose are exhibited in Fig. 2. Figure 2(a) presents the surface layer of the original ground EFB fibers, which consisted of packs of microfibrils with the deposition of non-cellulosic compounds such as lignin, wax, pectin, and hemicellulose. However, the surface of cellulose became smoothened and disordered after the pretreatment as shown in Fig. 2(b) and (c). 

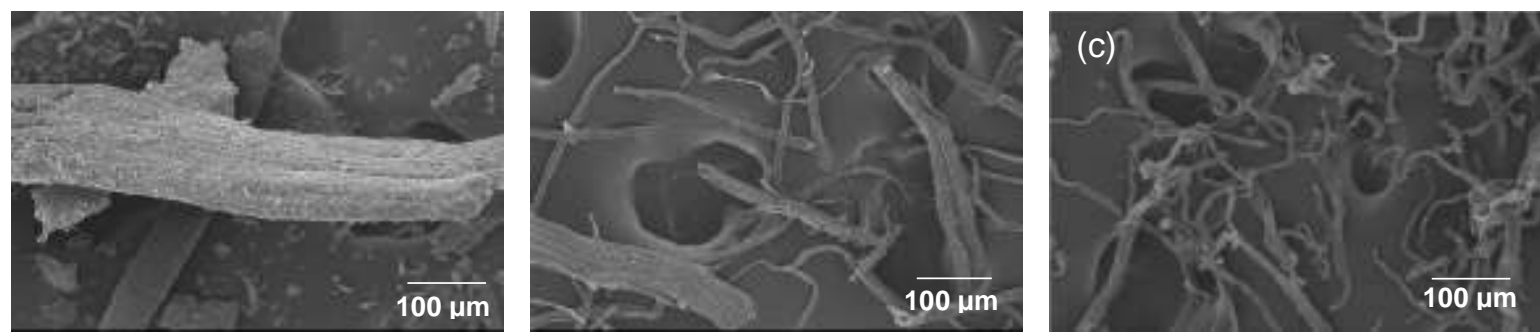

Fig. 2. SEM micrograph of EFB: (a) raw fiber, (b) unbleached DES-treated cellulose and (c) bleached DES-treated cellulose

The individualized fibers implied that the non-cellulosic components such as lignin and hemicellulose were removed considerably by the DES treatment and bleaching.

Figure 3(a), (b), and (c) show the FESEM, AFM, and TEM images, displaying the rod-like shape of acid hydrolyzed CNC from EFB. The dimension histograms (Fig. 4(a) and (b)) of acid-hydrolyzed CNC were illustrated based on the measurements of the data taken from the TEM micrograph. The diameter and length of CNC were investigated using digital image analysis (ImageJ), and values of $6.78 \pm 2.12 \mathrm{~nm}$ and $160.06 \pm 32.58$ $\mathrm{nm}$, respectively, with an aspect ratio of $25.47 \pm 8.13$ were observed. The aggregation of CNC could be observed in the micrograph. It could be due to the water evaporation step during sample preparation, drying method, and also the strong hydrogen bonding between CNC (Nagalakshmaiah et al. 2016).
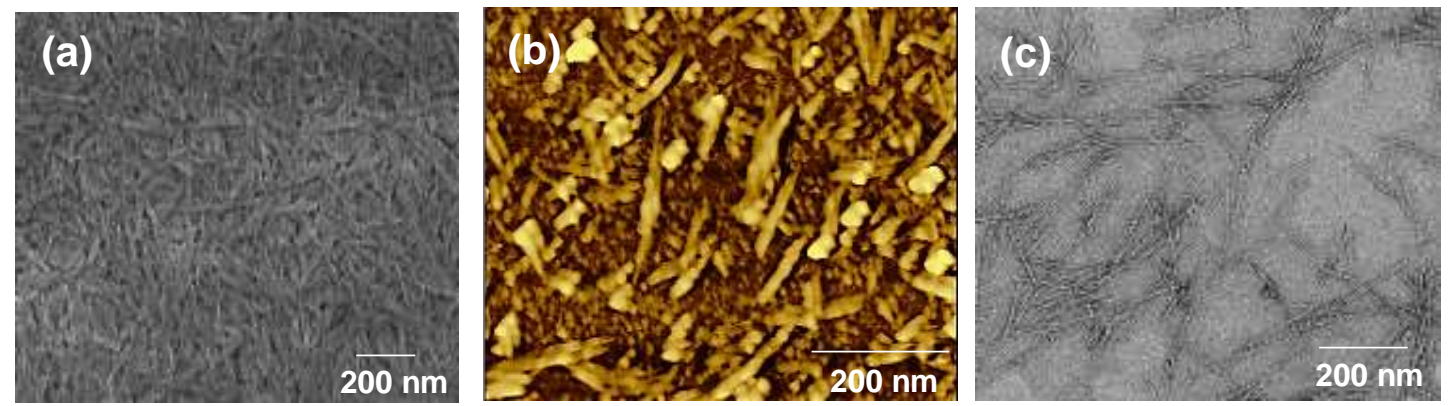

Fig. 3. (a) FESEM, (b) AFM, and (c) TEM micrographs of acid-hydrolyzed CNC

(a)

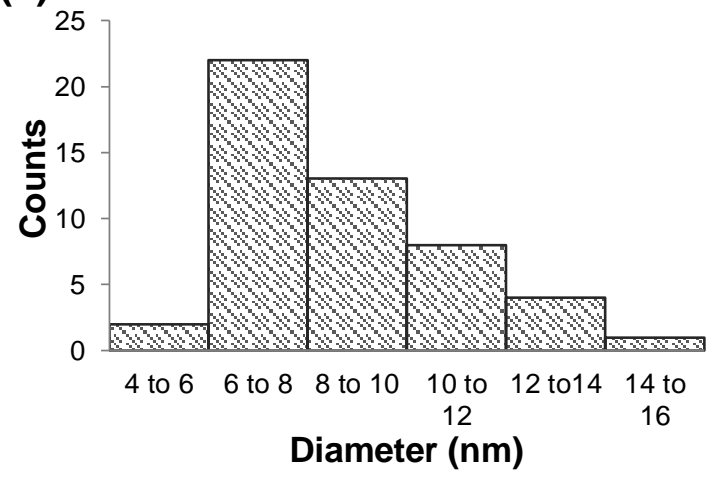

(b)

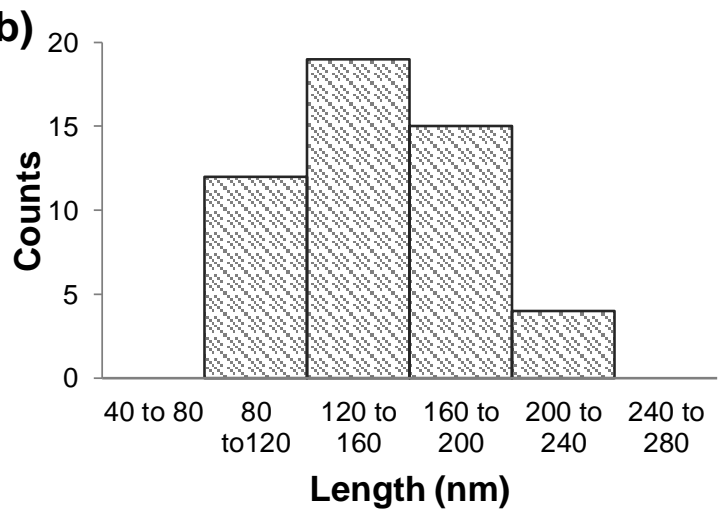

Fig. 4. (a) Diameter histogram and (b) length histogram of acid-hydrolyzed CNC 


\section{Chemical Composition Analysis}

The chemical compositions of raw EFB fibers, unbleached DES-treated cellulose, and bleached DES-treated cellulose are tabulated in Table 4. The raw EFB was comprised of $34.1 \%$ cellulose, $31.9 \%$ hemicellulose, and $25.9 \%$ lignin. After DES-pretreatment, the cellulose content was increased to $70.2 \%$, whereas the content of hemicellulose and lignin were decreased to $16.5 \%$ and $9.4 \%$, respectively. According to $\mathrm{Xu}$ et al. (2016), the changes could be explained by the swelling of cellulose and the removal of lignin and hemicellulose, resulting the enhanced cellulose accessibility under alkaline DES pre-treatment. Salehudin et al. (2014) reported a cellulose content of $90 \%$ after the alkaline treatment with $2.5 \mathrm{Mol} / \mathrm{L}$ sodium hydroxide followed by bleaching using sodium hypochlorite. The hemicellulose and lignin were removed notably by the subsequent bleaching treatment. These results reflected that the alkaline DES and bleaching treatment were able to remove the majority of the hemicellulose and lignin from the raw EFB fibers.

Table 4. Chemical Composition of Raw EFB Fibers, Unbleached DES-treated Cellulose and Bleached DES-treated Cellulose

\begin{tabular}{|c|c|c|c|}
\hline Specimens & Cellulose (\%) & Hemicellulose (\%) & Lignin (\%) \\
\hline Raw EFB & $34.1 \pm 0.8$ & $31.9 \pm 1.2$ & $25.9 \pm 0.6$ \\
\hline Unbleached DES-treated cellulose & $70.2 \pm 0.7$ & $16.5 \pm 0.7$ & $9.4 \pm 0.9$ \\
\hline Bleached DES-treated cellulose & $81.7 \pm 1.1$ & $9.4 \pm 0.8$ & $1.0 \pm 0.2$ \\
\hline
\end{tabular}

\section{FTIR Analysis}

The FTIR spectra of raw EFB fibers, unbleached DES-treated cellulose, bleached DES-treated cellulose, and CNC are displayed in Fig 5. The FTIR spectra for all cellulose exhibited a broad peak at $3410 \mathrm{~cm}^{-1}$, which was dominated by the stretching vibration of the $-\mathrm{OH}$ groups, whereas the peak at $2880 \mathrm{~cm}^{-1}$ was related to the $\mathrm{C}-\mathrm{H}$ stretching vibration. The shoulder peak at $1741 \mathrm{~cm}^{-1}$ in the spectra of the raw fibers was associated with the $\mathrm{C}=\mathrm{O}$ stretching of the uronic ester and acetyl groups, which are characteristic groups of hemicellulose (De Carvalho Benini et al. 2016). This group disappeared in the FTIR spectra of unbleached and bleached DES-treated cellulose, which suggested the elimination of hemicellulose after the treatments. The band at $1630 \mathrm{~cm}^{-1}$ was associated with the $\mathrm{OH}$ group of the water absorbed by the cellulose sample (Kallel et al. 2016). The reduction of intensity at the peak of $1630 \mathrm{~cm}^{-1}$ could be ascribed to the partial removal of hemicellulose from EFB fiber by pre-treatments (Chen et al. 2011). The small peak at $1235 \mathrm{~cm}^{-1}$ was associated with the C-O-C of the aryl group in lignin (Lani et al. 2014). The peak disappeared in after pre-treatments, which suggested the efficient elimination of lignin (Sheltami et al. 2012). Finally, the peak at $1050 \mathrm{~cm}^{-1}$ was related to the C-O stretching vibration. The spectrum of $\mathrm{CNC}$ was quite similar to that of raw EFB fiber, suggesting that the cellulose molecular structure was not affected by the acid hydrolysis. 


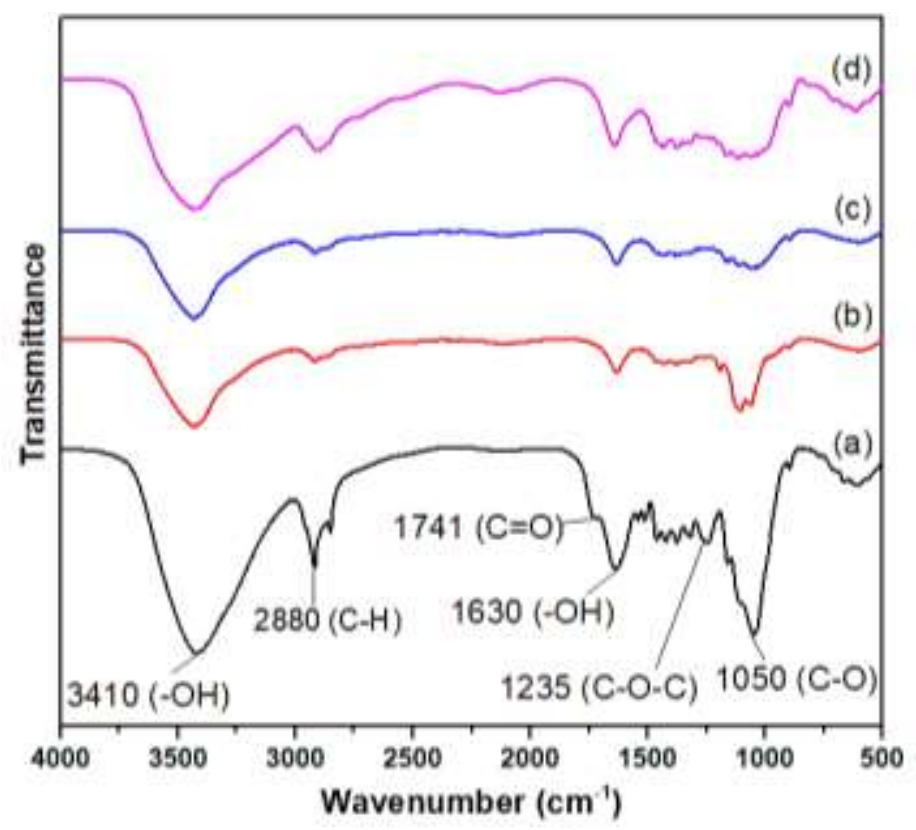

Fig. 5. FTIR Spectra of EFB (a) raw fiber, (b) unbleached DES-treated cellulose, (c) bleached DES-treated cellulose and CNC

The removal of lignin and hemicellulose by DES treatment and bleaching is depicted in Fig. 6. The DES treatment and bleaching were shown to have successfully removed most of the non-cellulosic components (lignin and hemicellulose) from the raw EFB fiber.

Fig. 6. Schematic of the effect of DES treatment and bleaching on EFB cellulose

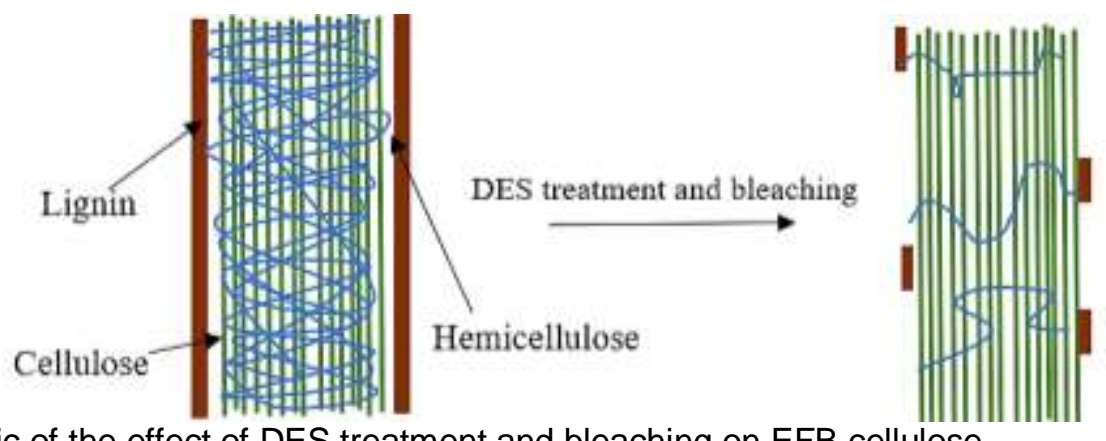

\section{XRD Analysis}

The XRD profiles of raw EFB fibers, unbleached DES-treated cellulose, bleached DES-treated cellulose, and CNC are shown in Fig. 7. All diffractograms showed peaks around $16^{\circ}, 22.5^{\circ}$, and $34^{\circ}$, which were associated with the diffraction planes of (101), (002), and (040), respectively. This indicated the crystal lattice of cellulose type I (Kunaver et al. 2016). Similar curves and peaks of diffractograms of CNC exhibited that the acid hydrolysis did not interrupt the structure of the cellulose. Meanwhile, the peak intensity of the (002) plane was increased significantly after pretreatments. This indicated that the cellulose became more crystalline after the treatments due to the elimination of amorphous structures such as hemicellulose and lignin (Le Normand et al. 2014). 


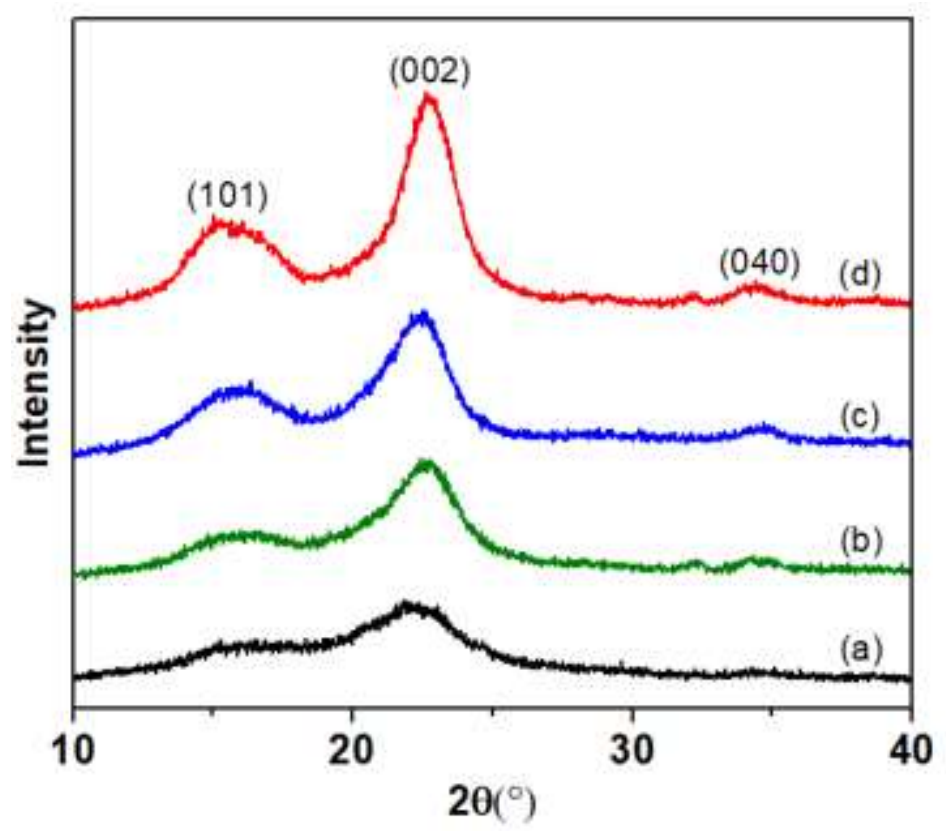

Fig. 7. X-ray diffractogram of EFB (a) raw fiber, (b) unbleached DES-treated cellulose, (c) bleached DES-treated cellulose and (d) CNC

The CI of the EFB cellulose samples is presented in Table 5. The CI of the cellulose increased from $38.7 \%$ for raw fiber to $46.5 \%$ for unbleached DES-treated cellulose and was further enhanced to $51.2 \%$ for bleached DES treated cellulose. The crystallinity of the bleached DES-treated cellulose was comparable to the cellulose treated via conventional treatments, i.e., alkaline treatment and bleaching, which was 52.1\% (Owi et al. 2017). The increase in crystallinity proved that the DES treatment was capable of removing the non-cellulosic components (lignin and hemicellulose) efficiently. The CNC was observed to have the highest crystallinity index. The sulphuric acid hydrolysis treatment applied to prepare the CNC had selectively hydrolyzed the amorphous domains, surrounding and embedding the cellulose but leaving the crystalline segments intact (Sofla et al. 2016). Hence, the crystallinity of CNC further increased with the sulphuric acid hydrolysis treatment. The $\mathrm{CNC}$ isolated in this study presented a higher crystallinity compared to those isolated by Fahma et al. (2010) and Saurabh et al. (2016), which was around 59\% and 55\%, respectively, using EFB fibers. Furthermore, sulphuric acid hydrolyzed CNC presented higher crystallinity than other acids such as hydrochloric acid and mixture of acetic acid and nitric acid which were found to be $61.0 \%$ and $61.8 \%$ as reported by Zhang et al. (2014).

Table 5. Percentage of Crystallinity of Raw EFB Fibers, Unbleached DEStreated Cellulose, Bleached DES-treated Cellulose and CNC

\begin{tabular}{|c|c|}
\hline Samples & Crystallinity Index (\%) \\
\hline Raw fiber & 38.7 \\
\hline Unbleached DES-treated cellulose & 46.5 \\
\hline Bleached DES-treated cellulose & 51.2 \\
\hline CNC & 65.3 \\
\hline
\end{tabular}




\section{Thermogravimetric Analysis}

Figure 8 displays the TG and DTG curves of raw fiber, unbleached DEStreated cellulose, bleached unbleached DES-treated cellulose, and CNC from EFB fibers. Three main events of weight loss were observed in the thermogram, which were the evaporation of water from fiber (A), the decomposition of non-cellulosic components and pyrolysis of cellulose (B), and the decomposition of lignin (C). A slight weight loss between $30{ }^{\circ} \mathrm{C}$ and $110{ }^{\circ} \mathrm{C}$ was observed in section $\mathrm{A}$, which was attributed to the evaporation of the water from the specimens that associated with the physisorbed and/or chemisorbed water (Kiziltas et al. 2015). The weight loss was influenced by the initial moisture content of the fiber samples.

Due to the lower thermal stability of non-cellulosic components, such as lignin and hemicellulose, the raw EFB fiber displayed an earlier weight loss, which began at an approximately $180{ }^{\circ} \mathrm{C}$ and reached a maximum decomposition at $332{ }^{\circ} \mathrm{C}$. This accounted for the cellulose pyrolysis via reactions of depolymerization, dehydration, and decomposition of glycoside units (Chen et al. 2015). In contrast, the cellulose presented a higher initial decomposing temperature and temperature at maximum decomposition at $200{ }^{\circ} \mathrm{C}$ and $320{ }^{\circ} \mathrm{C}$ after alkaline DES pre-treatment. The higher decomposition temperature suggested that the removal of hemicellulose and lignin from the EFB fibers (Draman et al. 2016b). In addition, the subsequent bleaching treatment further increased the thermal stability of the cellulose. The bleached DES treated cellulose presented a maximum decomposition temperature at $344{ }^{\circ} \mathrm{C}$. Razali et al. (2017) reported a maximum decomposition temperature of $328{ }^{\circ} \mathrm{C}$ for cellulose from EFB pulp using hydrochloric acid pretreatment at $2.5 \mathrm{~N}$ concentration at $105^{\circ} \mathrm{C}$ for $20 \mathrm{~min}$ (Razali et al. 2017)(Razali et al. 2017)(Razali et al. 2017). The bleached DES-treated cellulose also exhibited a comparable maximum decomposition temperature compared to those reported by Owi et al. (2016). Alkaline treatment and bleaching were applied in isolation of cellulose, and the maximum decomposition temperature was approximately $345{ }^{\circ} \mathrm{C}$. However, the $\mathrm{CNC}$ showed a different degradation behavior from the raw fiber and treated cellulose. A lower initial decomposition temperature and maximum decomposition temperature at $200{ }^{\circ} \mathrm{C}$ and $272{ }^{\circ} \mathrm{C}$ were detected. The diminished thermal stability of $\mathrm{CNC}$ was attributed to the introduction of the sulphate group during sulphuric acid hydrolysis, which reduced the activation energy required for degradation, making the cellulose more accessible to pyrolysis (Kallel et al. 2016). 

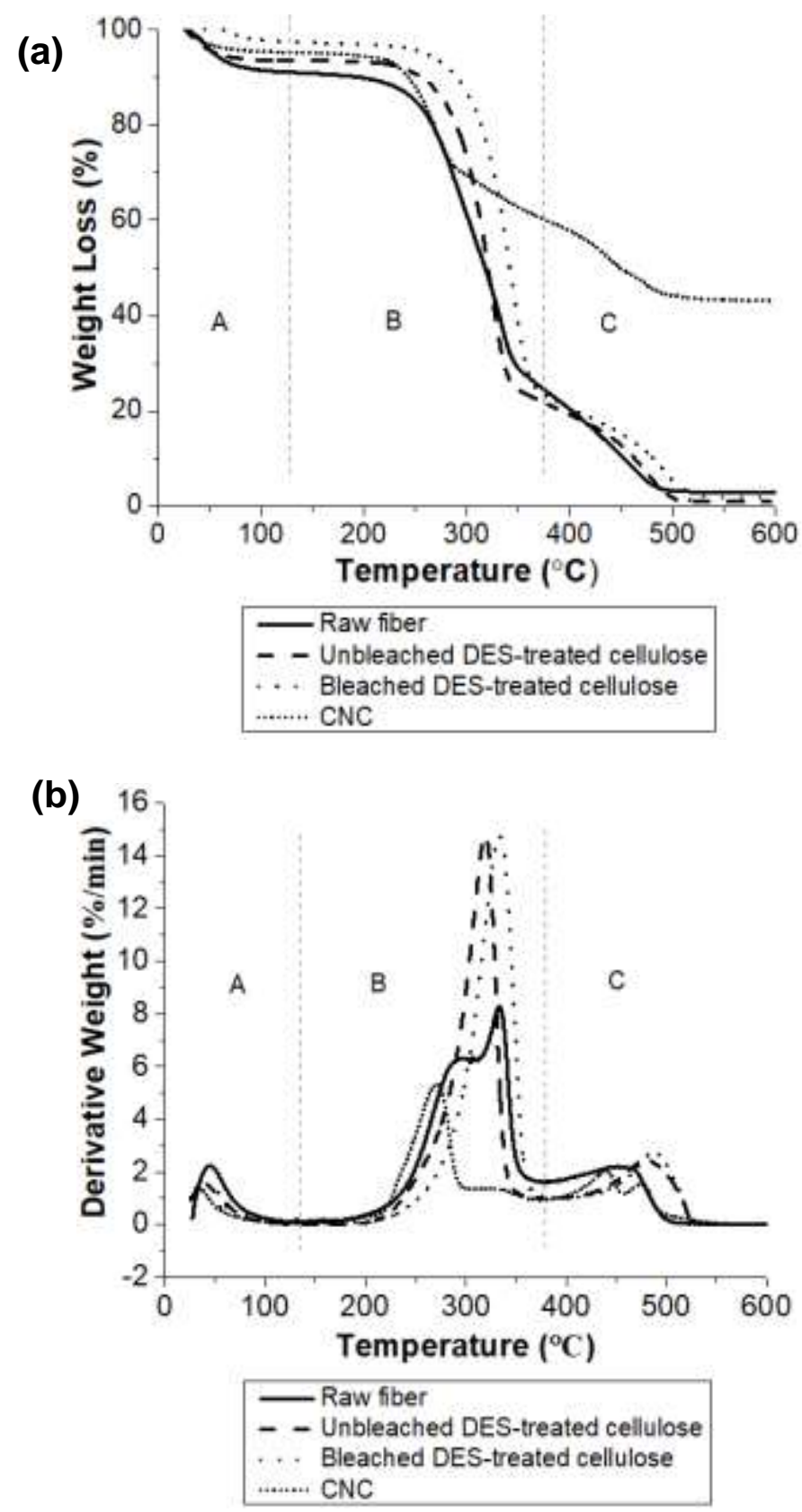

Fig. 8. (a) TG and (b) DTG curves of raw fiber, unbleached DES-treated cellulose, bleached DES-treated cellulose and CNC of EFB

The degradation of lignin happened concurrently with other degradation processes and may have remained as a residue at the end of degradation, ranging from room temperature to $700{ }^{\circ} \mathrm{C}$, as shown in region $\mathrm{C}$ (Sabaruddin and Paridah 2018). This was due to the complex structure of lignin that made up of the aromatic rings with numerous branches (Hua et al. 2016). At the temperature range between $400{ }^{\circ} \mathrm{C}$ to 600 ${ }^{\circ} \mathrm{C}$, a shoulder peak was observed for all cellulose samples. It could be assigned to the decomposition of lignin, dehydration, yielding derivatives with lateral unsaturated chains and water, carbon dioxide, carbon monoxide, and the release of methane gas (De Carvalho Benini et al. 2016). The amount of charred residues of CNC (approximately $42 \%$ ) was considerably higher than other cellulose samples that could have been due to 
the presence of the sulphate group, which promoted dehydration and acted as a flame retardant (Bettaieb et al. 2015). Due to the small particle size, CNC has a large number of free end chains, which caused the decomposition to begin at a lower temperature and eventually led to a higher amount of charred residue (Sofla et al. 2016).

\section{CONCLUSIONS}

1. Cellulose nanocrystals (CNC) were successfully isolated from empty fruit bunch (EFB) by acid hydrolysis with deep eutectic solvent (DES) as pretreatment. The DES and bleaching treatments were efficient in removing the lignin and hemicellulose based on a high crystallinity and thermostability of cellulose after the treatments.

2. The CNC produced by sulphuric acid hydrolysis had even higher crystallinity with a diameter of less than $10 \mathrm{~nm}$.

3. The thermal stability of CNC declined after acid hydrolysis, which was due to the presence of a sulphate group, which acted as a flame retardant.

4. Due to the low toxicity, biocompatibility, and biodegradability of the solvent, DES pretreatment can be employed as an environmentally friendly alternative for the production of $\mathrm{CNC}$.

\section{ACKNOWLEDGMENTS}

This research was supported by the Fundamental Research Grant Scheme (FRGS/1/2015/TK10/UNIMAP/03/5) from the Malaysia Ministry of Higher Education.

\section{REFERENCES CITED}

Bettaieb, F., Khiari, R., Dufresne, A., Mhenni, M. F., and Belgacem, M. N. (2015). "Mechanical and thermal properties of Posidonia oceanica cellulose nanocrystal reinforced polymer," Carbohydrate Polymers 123, 99-104.

DOI:10.1016/j.carbpol.2015.01.026.

Cao, Y. (2018). "Applications of cellulose nanomaterials in pharmaceutical science and pharmacology," Express Polymer Letters 12(9), 768-780.

DOI:10.3144/expresspolymlett.2018.66.

Chao, L., Bin, L., Haishun, D., Dong, L., Yuedong, Z., Guang, Y., Xindong, M., and Hui, P. (2016). "Properties of nanocellulose isolated from corncob residue using sulfuric acid, formic acid, oxidative and mechanical methods," Carbohydrate Polymers 151, 716-724. DOI: 10.1016/j.carbpol.2016.06.025

Chen, X., Yu, J., Zhang, Z., and Lu, C. (2011). "Study on structure and thermal stability properties of cellulose fibers from rice straw," Carbohydrate Polymers 85(1), 245250. DOI:10.1016/j.carbpol.2011.02.022.

Chen, Y., Wu, Q., Huang, B., Huang, M., and Ai, X. (2015). "Isolation and characteristics of cellulose and nanocellulose from lotus leaf stalk agro-wastes," BioResources 10(1), 684-696. DOI: 10.15376/biores.10.1.684-696

Chieng, B. W., Lee, S. H., Ibrahim, N. A., Then, Y. Y., and Loo, Y. Y. (2017). "Isolation 
and characterization of cellulose nanocrystals from oil palm mesocarp fiber," Polymers 9(8), 355. DOI:10.3390/polym9080355.

de Carvalho Benini, K. C. C., Voorwald, H. J. C., Cioffi, M. O. H., Milanese, A. C., and Ornaghi Jr, H. L. (2016). "Characterization of a new lignocellulosic fiber from Brazil: Imperata brasiliensis (Brazilian satintail) as an alternative source for nanocellulose extraction," Journal of Natural Fibers 14(1), 112-125. DOI:10.1080/15440478.2016.1167647.

Draman, S. F. S., Daik, R., and Mohd, N. (2016a). "Eco-friendly extraction and characterization of cellulose from lignocellulosic fiber," ARPN Journal of Engineering and Applied Sciences 11(16), 9591-9595.

Draman, S. F. S., Daik, R., and Mohd, N. (2016b). "Eco-friendly extraction and characterization of cellulose from lignocellulosoic fiber," ARPN Journal of Engineering and Applied Sciences 11(16), 9591-9595.

Duret, X., Fredon, E., Masson, E., Desharnais, L., and Gérardin, P. (2013). “Optimization of acid pretreatment in order to increase the phenolic content of Picea abies bark by surface response methodology," BioResources, 8(1), 1258-1273. DOI:10.15376/biores.8.1.1258-1273.

Fahma, F., Iwamoto, S., Hori, N., Iwata, T., and Takemura, A. (2010). "Isolation, preparation, and characterization of nanofibers from oil palm empty-fruit-bunch (OPEFB)," Cellulose 17(5), 977-985. DOI:10.1007/s10570-010-9436-4.

Hua, W., Liu, C., Wu, S., and Li, X. (2016). "Analysis of structural units and their influence on thermal degradation of alkali lignins," BioResources 11(1), 1959-1970. DOI:10.15376/biores.11.1.1959-1970.

Islam, M. S., Kao, N., Bhattacharya, S. N., Gupta, R., and Choi, H. J. (2018). "Potential aspect of rice husk biomass in Australia for nanocrystalline cellulose production," Chinese Journal of Chemical Engineering 26(3), 465-476.

DOI:10.1016/j.cjche.2017.07.004.

Kallel, F., Bettaieb, F., Khiari, R., García, A., Bras, J., and Chaabouni, S. E. (2016). "Isolation and structural characterization of cellulose nanocrystals extracted from garlic straw residues," Industrial Crops and Products 87, 287-296. DOI:10.1016/j.indcrop.2016.04.060.

Kiziltas, E. E., Kiziltas, A., and Gardner, D. J. (2015). "Synthesis of bacterial cellulose using hot water extracted wood sugars," Carbohydrate Polymers 124, 131-138. DOI:10.1016/j.carbpol.2015.01.036.

Kunaver, M., Anžlovar, A., and Žagar, E. (2016). "The fast and effective isolation of nanocellulose from selected cellulosic feedstocks," Carbohydrate Polymers 148, 251-258. DOI:10.1016/j.carbpol.2016.04.076.

Lani, N. S., Ngadi, N., Johari, A., and Jusoh, M. (2014). "Isolation, characterization, and application of nanocellulose from oil palm empty fruit bunch fiber as nanocomposites," Journal of Nanomaterials 2014. DOI:10.1186/s12934-014-0157-5

Leite, A. L. M. P., Zanon, C. D., and Menegalli, F. C. (2017). "Isolation and characterization of cellulose nanofibers from cassava root bagasse and peelings," Carbohydrate Polymers 157, 962-970. DOI:10.1016/j.carbpol.2016.10.048.

Li, P., Sirviö, J. A., Asante, B., and Liimatainen, H. (2018). "Recyclable deep eutectic solvent for the production of cationic nanocelluloses," Carbohydrate Polymers 199, 219-227. DOI:10.1016/j.carbpol.2018.07.024.

Lu, Z., Fan, L., Zheng, H., Lu, Q., Liao, Y., and Huang, B. (2013). 'Preparation, characterization and optimization of nanocellulose whiskers by simultaneously 
ultrasonic wave and microwave assisted," Bioresource Technology 146, 82-88.

DOI:10.1016/j.biortech.2013.07.047.

Lynam, J. G., Kumar, N., and Wong, M. J. (2017). “Deep eutectic solvents' ability to solubilize lignin, cellulose, and hemicellulose; thermal stability; and density," Bioresource Technology 238, 684-689. DOI:10.1016/j.biortech.2017.04.079.

Martelli-Tosi, M., Masson, M. M., Silva, N. C., Esposto, B. S., Barros, T. T., Assis, O. B. G., and Tapia-Blácido, D. R. (2018). "Soybean straw nanocellulose produced by enzymatic or acid treatment as a reinforcing filler in soy protein isolate films," Carbohydrate Polymers 198, 61-68. DOI:10.1016/j.carbpol.2018.06.053.

Mohanty, S., Nayak, S. K., Kaith, B. S., and Kalia, S. (2015). Polymer Nanocomposites based on Inorganic and Organic Nanomaterials, Polymer Science and Plastics Engineering, Wiley.

Nagalakshmaiah, M., Kissi, N. El, Mortha, G., and Dufresne, A. (2016). "Structural investigation of cellulose nanocrystals extracted from chili leftover and their reinforcement in cariflex-IR rubber latex," Carbohydrate Polymers 136, 945-954. DOI:10.1016/j.carbpol.2015.09.096.

Normand, M. Le, Moriana, R., and Ek, M. (2014). "Isolation and characterization of cellulose nanocrystals from spruce bark in a biorefinery perspective," Carbohydrate Polymers 111, 979-987. DOI:10.1016/j.carbpol.2014.04.092.

Owi, W. T., Lin, O. H., Sam, S. T., Chia, C. H., Zakaria, S., Mohaiyiddin, M. S., Villagracia, A. R., Santos, G. N., and Akil, H. M. (2016). "Comparative study of microcelluloses isolated from two different biomasses with commercial cellulose," BioResources 11(2), 3453-3465. DOI:10.15376/biores.11.2.3453-3465.

Owi, W. T., Lin, O. H., Sam, S. T., Villagracia, A. R., and Santos, G. N. C. (2017). "Tapioca starch based green nanocomposites with environmental friendly crosslinker," Chemical Engineering Transactions 56, 463-468.

DOI:10.3303/CET1756078.

Razali, N., Hossain, M. S., Taiwo, O. A., Ibrahim, M., Nadzri, N. W. M., Razak, N., Rawi, N. F. M., Mahadar, M. M., and Kassim, M. H. M. (2017). "Influence of acid hydrolysis reaction time on the isolation of cellulose nanowhiskers from oil palm empty fruit bunch microcrystalline cellulose," BioResources 12(3), 6773-6788. DOI:10.15376/biores. 12.3.6773-6788.

Sabaruddin, F. A., and Paridah, M. T. (2018). "Effect of lignin on the thermal properties of nanocrystalline prepared from kenaf core," IOP Conference Series: Materials Science and Engineering DOI:10.1088/1757-899X/368/1/012039.

Salehudin, M. H., Salleh, E., Mamat, S. N. H., and Muhamad, I. I. (2014). "Starch based active packaging film reinforced with empty fruit bunch (EFB) cellulose nanofiber," Procedia Chemistry 9, 23-33. DOI:10.1016/j.proche.2014.05.004.

Saurabh, C. K., Dungani, R., Owolabi, A. F., Atiqah, N. S., Zaidon, A., Aprilia, N. A. S., Sarker, Z. M., and Abdul Khalil, H. P. S. (2016). "Effect of hydrolysis treatment on cellulose nanowhiskers from oil palm (Elaeis guineesis) fronds: Morphology, chemical, crystallinity, and thermal characteristics," BioResources 11(3), 67426755.

Segal, L., Creely, J. J., Martin, A. E., and Conrad, C. M. (1959). “An empirical method for estimating the degree of crystallinity of native cellulose using the X-ray diffractometer," Textile Research Journal 29(10), 786-794. DOI:10.1177/004051755902901003.

Sheltami, R. M., Abdullah, I., Ahmad, I., Dufresne, A., and Kargarzadeh, H. (2012). 
"Extraction of cellulose nanocrystals from mengkuang leaves (Pandanus tectorius)," Carbohydrate Polymers 88(2), 772-779. DOI:10.1016/j.carbpol.2012.01.062.

Singh, S., Cheng, G., Sathitsuksanoh, N., Wu, D., Varanasi, P., George, A., Balan, V., Gao, X., Kumar, R., Dale, B. E., Wyman, C. E., and Simmons, B. A. (2015). "Comparison of different biomass pretreatment techniques and their impact on chemistry and structure," Frontiers in Energy Research 2, 1-12. DOI:10.3389/fenrg.2014.00062.

Siqueira, G., Tapin-Lingua, S., Bras, J., da Silva Perez, D., and Dufresne, A. (2010). "Morphological investigation of nanoparticles obtained from combined mechanical shearing, and enzymatic and acid hydrolysis of sisal fibers," Cellulose 17(6), 11471158. DOI:10.1007/s10570-010-9449-z.

Sofla, M. R. K., Brown, R. J., Tsuzuki, T., and Rainey, T. J. (2016). “A comparison of cellulose nanocrystals and cellulose nanofibres extracted from bagasse using acid and ball milling methods," Advances in Natural Sciences: Nanoscience and Nanotechnology 7(3), 35-44. DOI:10.1088/2043-6262/7/3/035004.

Thakur, V. K. (2014a). Lignocellulosic Polymer Composites: Processing, Characterization, and Properties. Polymer Science and Plastics Engineering, Wiley.

Thakur, V. K. (2014b). Nanocellulose Polymer Nanocomposites: Fundamentals and Applications. Polymer Science and Plastics Engineering, Wiley.

Vanda, H., Dai, Y., Wilson, E. G., Verpoorte, R., and Choi, Y. H. (2018). "Green solvents from ionic liquids and deep eutectic solvents to natural deep eutectic solvents," Comptes Rendus Chimie 21(6), 628-638. DOI:10.1016/j.crci.2018.04.002.

Xia, S., Baker, G. A., Li, H., Ravula, S., and Zhao, H. (2014). "Aqueous ionic liquids and deep eutectic solvents for cellulosic biomass pretreatment and saccharification," RSC Advances 4(21), 10586-10596. DOI:10.1039/c3ra46149a.

$\mathrm{Xu}, \mathrm{H}$., Li, B., and Mu, X. (2016). "Review of alkali-based pretreatment to enhance enzymatic saccharification for lignocellulosic biomass conversion," Industrial and Engineering Chemistry Research 55(32), 8691-8705. DOI:10.1021/acs.iecr.6b01907.

Yang, X., Han, F., Xu, C., Jiang, S., Huang, L., Liu, L., and Xia, Z. (2017). "Effects of preparation methods on the morphology and properties of nanocellulose (NC) extracted from corn husk," Industrial Crops and Products 109, 241-247. DOI:10.1016/j.indcrop.2017.08.032.

Zhang, P. P., Tong, D. S., Lin, C. X., Yang, H. M., Zhong, Z. K., Yu, W. H., Wang, H., and Zhou, C. H. (2014). "Effects of acid treatments on bamboo cellulose nanocrystals," Asia-Pacific Journal of Chemical Engineering 9(5), 686-695. DOI:10.1002/apj.1812

Article submitted: July 26, 2019; Peer review completed: October 10, 2019; Revised version received: December 4, 2019; Accepted: December 5, 2019; Published: January 2, 2020.

DOI: 10.15376/biores.15.1.1154-1170 